\title{
Changes in investors' risk appetite - an assessment of financial integration and interdependence ${ }^{1}$
}

\author{
Laurence Kang-por Fung ${ }^{2}$, Chi-sang $\mathrm{Tam}^{3}$ and Ip-wing $\mathrm{Yu}^{4}$
}

\section{Introduction}

Investors' attitude towards risk has increasingly been cited as a key factor driving the movement in asset prices. A systematic shift in investors' attitude towards risk, or a decline in investors' risk appetite, may cause correlation among prices of different financial assets, thus undermining financial stability and heightening the risk of financial contagion. Therefore, it is important to central banks to have the necessary tools that allow the policy makers to track the dynamics of investors' risk appetite and understand the possible linkages between risk appetites across different markets. However, in recent studies, the focus is mainly on developing indicators to measure the risk appetite and showing the coincidence between episodes of financial turmoil in individual countries and abrupt declines in market sentiment from risk seeking to risk avoidance. ${ }^{5}$

This paper contributes to the literature by applying the risk appetite measure to central banks' monitoring work in two aspects. First, it investigates whether changes in the risk appetite are correlated among different economies (the United States (US), the United Kingdom (UK), Germany, Japan and Hong Kong SAR (HK SAR) in this paper) and provides a measure of financial integration between them. Second, by examining the degree of comovement between the risk appetite measures and the stock and bond market performance, it sheds the light on the interdependence between the stock and bond markets in these economies, which may give rise to possible contagion risk during financial market turmoil.

The remainder of this paper is organised as follows. In Section II, we provide a brief discussion on how we derive the risk appetite measures for the five economies. In this study, the derivation of the risk appetite measures is based on the methodology recently proposed by Gai and Vause (2006). Section III reviews the issues related to financial integration and provides the various integration indicators used in this study. The estimation results of the integration indicators and the empirical evidence of financial market interdependence based on dynamic conditional correlations are presented in Section IV. Section V is a summary and conclusion.

1 The views and analysis expressed in this paper are those of the authors, and do not necessarily represent the views of the Hong Kong Monetary Authority (HKMA). The authors are grateful to Hans Genberg and Chohoi Hui for their useful comments. We are also thankful to Ronald Ka-wai Leung, who worked as a summer intern at the HKMA in 2007, for his outstanding research assistance. The assistance of the Chicago Board Options Exchange (CBOE) in providing historical S\&P 500 Index Options data is gratefully acknowledged. All remaining errors are ours. Hong Kong Monetary Authority; Laurence_KP_Fung@hkma.gov.hk.

3 Hong Kong Monetary Authority; Chi-sang_Tam@hkma.gov.hk.

$4 \quad$ Hong Kong Monetary Authority; Ip-wing_Yu@hkma.gov.hk.

5 A survey of risk appetite indicators can be found in Illing and Aaron (2005). 


\section{Measure of investors' risk appetite}

The degree of investors' risk appetite can not be observed directly in the market. In the literature, there are different market-based and theory-based risk appetite measures proposed by financial institutions, central banks as well as international organisations for monitoring purposes. ${ }^{6}$ In this study, we utilise the methodology recently developed by Gai and Vause (2006) to derive the risk appetite measure which has its origin from the basic pricing equation in the asset pricing theory. ${ }^{7}$ While the analysis of asset pricing shows that risky assets can be priced by evaluating the expectation of discounted payoffs in terms of investors' subjective probabilities about various states of the world, risk-free asset can be equivalently determined by discounting payoffs using the risk-free rate and evaluating expectations based on a set of risk-neutral probabilities. In their paper, Gai and Vause show that the measure of risk appetite can be determined once the subjective and the risk-neutral probability density functions over future asset returns are estimated.

This study follows Gai and Vause's method and estimates the investor's subjective and the risk-neutral probability density (RND) functions over future asset returns, in this case the stock market returns. The underlying stock market indices of the five economies where investors' risk appetite measures are derived are:

\begin{tabular}{c|c}
\hline Economy & Benchmark stock market index \\
\hline The United States & S\&P 500 Index \\
The United Kingdom & FTSE 100 Index \\
Germany & DAX 30 Index \\
Japan & Nikkei 225 Stock Average \\
Hong Kong SAR & Hang Seng Index \\
\hline
\end{tabular}

The benchmark stock market indices are taken from CEIC. Historical S\&P 500 Index Option data are provided by the Chicago Board Options Exchange (CBOE), while the index option data of other stock market indices are taken from Bloomberg. For each underlying stock market index, seven spot month contracts are considered for the RND estimation. These seven contracts have strike prices at the current index level and at three strike intervals above and below the current index level. ${ }^{8}$ The risk-free interest rate used in the RND

6 Examples of risk appetite measures include the JPMorgan Liquidity, Credit and Volatility Index (LCVI), the Merrill Lynch Financial Stress Index, the State Street's Investor Confidence Index, the Credit Suisse First Boston Risk Appetite Index, the Goldman Sachs Risk Aversion Index, the Chicago Board Options Exchange Volatility Index (VIX), the Kumar and Persaud (2002) Global Risk Appetite Index (GRAI) used by the IMF, the Tarashev et al. (2003) Risk Appetite Index used by the BIS, and the Gai and Vause (2006) Risk Appetite Index used by the Bank of England and the HKMA. Illing and Aaron (2005) provide a brief survey of these risk appetite measures.

7 The approach by Gai and Vause (2006) has some advantages over other alternative measures. For instance, the index developed by Gai and Vause is easier to interpret than the JPMorgan LCVI because of the latter's ad hoc methodology to aggregate different financial risks.

$8 \quad$ The strike interval is different for different stock market index options. It is 5 index points for the S\&P 500 Index Option, 25 index points for the FT100 Index Option, 50 index points for the DAX 30 Index Option, 500 index points for the Nikkei 225 Stock Average index Option, and 200 index points for the Hang Seng Index Option. 
estimation is the one-month interbank rate of the respective economy. ${ }^{9}$

According to Gai and Vause (2006), the unit price of risk $\left(\lambda_{t}\right)$ at time $t$ can be derived as:

$$
\lambda_{t}=\frac{1}{R_{t+1}^{f}} \operatorname{var}\left(\frac{f_{t+1}^{*}(s)}{f_{t+1}(s)}\right)
$$

where $R_{t}^{f}$ is the gross risk-free rate of return at time $t, f_{t}^{*}(s)$ is the RND of the asset price $s$ at time $t, f_{t}(s)$ is the subjective history implied density function of the asset price $s$ at time $t$, and $\operatorname{var}()$ is the variance operator. The unit price of risk $\lambda$ is the expected excess return that investors require to hold each unit of risk of an asset in equilibrium. Risk appetite, which is the willingness of investors to bear risk, can therefore be defined as the natural logarithm of the inverse of $\lambda$.

In this study, similar to Gai and Vause, the subjective probability distribution of future asset returns is derived from the GARCH $(1,1)$ model, while the risk-neutral density function is estimated by option prices using the two-lognormal mixture models. Full details of the estimation methodology are given in Appendix I.

Figure 1 shows the movements of the derived risk appetite measures for investors in the stock markets of the US, the UK, Germany (Figure 1a), Japan and HK SAR (Figure 1b) from their earliest data available up to December 2007. ${ }^{10}$ Higher values of this measure are interpreted as an indication of higher risk appetite (higher investor tolerance of risk) for investors.

Figure 1

\section{Risk appetite measures of different stock markets}

(a) The US, the UK and Germany

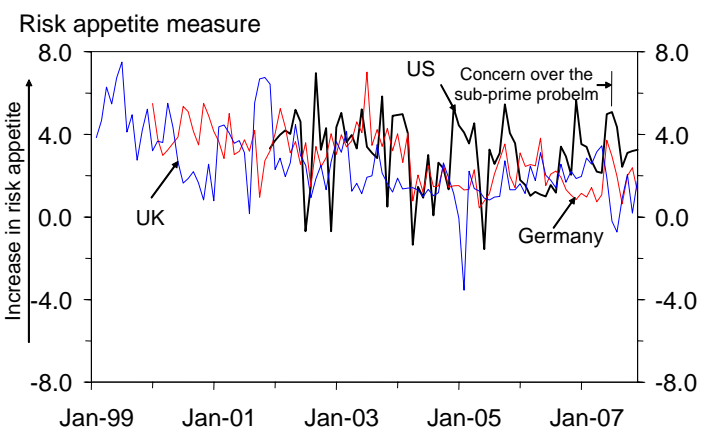

(b) Japan and HK SAR

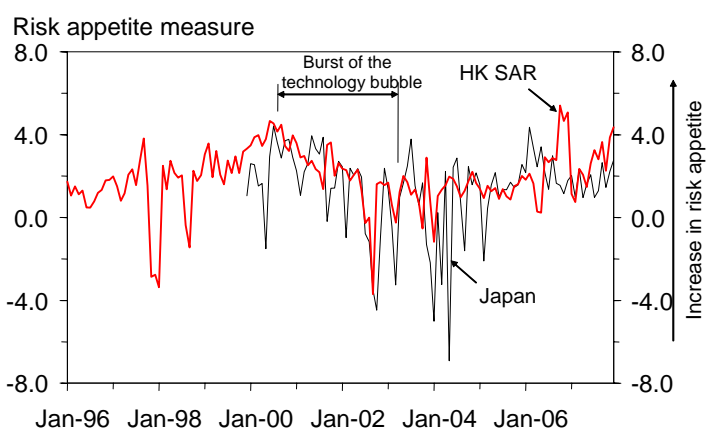

Source: HKMA staff estimates.

9 For the US, it is the US dollar London Interbank Offered Rate (LIBOR). The British Pound LIBOR for the UK, the Frankfurt Interbank Offered Rate for Germany, the Tokyo Interbank Offered Rate for Japan and the Hong Kong Interbank Offered Rate for HK SAR. Data are taken from Bloomberg.

10 The starting dates of the risk appetite measures vary due to the availability of index option data. The risk appetite measure for the US starts from December 2001. It is February 1999 for the UK, January 2000 for Germany, December 1999 for Japan and January 1996 for HK SAR. 
Similar to the observation by Illing and Aaron (2005), the risk appetite measures in the two graphs in Figure 1 are quite volatile. Despite this, they generally conform to the asset price swings in recent episodes of extreme market sentiment. For example, in the case of the US in Figure 1a, the risk appetite measure declined when the sub-prime problem and the subsequent credit crunch emerged in July-August 2007. In the case of HK SAR in Figure 1b, the risk appetite measure dropped abruptly to a low level during the period between October 1997 and January 1998 amid the speculative attack against the HK SAR dollar resulting in great financial market distress. The burst of the "technology bubble" in mid-2000 and the subsequent bear market until the end of 2002 coincided with the gradual decline of the risk appetite measure. The bull run in the HK SAR stock market starting from the second half of 2006 was also reflected in the sharp rise of the measure.

In the analyses that follow, we investigate the financial market integration and contagion issues through the examination of the risk appetite measures and their interactions with the stock and bond markets. ${ }^{11}$

\section{Financial integration and integration indicators}

There is, in general, no universal definition of financial integration. Financial openness, free movement of capital and integration of financial services are part of a broad range of definition frequently cited in the literature. ${ }^{12}$ One commonly used definition of financial integration is that financial markets are said to be integrated when the law of one price holds. Korajczyk (1995) notes that if markets are financially integrated, the price of risk should be the same across markets. Since the Gai and Vause's measure of risk appetite is defined as the inverse of the price of risk, we make use of their measure and study the issue of financial integration by investigating whether investors' willingness to bear risk is the same across different markets.

For monitoring purposes, it is desirable for policy makers to have indicators that are frequently available. In this study, we use monthly data to construct several indicators to measure different dimensions of market integration in the five stock markets (namely the US, the UK, Germany, Japan and HK SAR), including

1. cross-market dispersion and correlation;

2. the component factors based on the principal component analysis;

3. $\quad$ time-varying $\beta$ estimated via Haldane and Hall (1991) Kalman filter method; and

4. dynamic conditional correlation. ${ }^{13}$

These indicators are mainly model-based and provide high frequency measures for regular monitoring purposes (see Table 1 below for a summary of the integration indicators in this study). Detailed discussions on the methodologies of constructing these indicators and their interpretation are presented in Appendix II. Given that the construction of these indicators is

11 The examination is based on both the changes of these measures and also the levels when it is appropriate.

12 In some studies, regulatory and institutional factors such as the relaxation of capital controls, financial liberalisation, prudential regulations, efficiency of the legal systems and the standardisation of market framework are also cited as measures of financial integration. These measures, however, are less popular than price-based measures in a regular monitoring framework as they are not timely available.

13 Changes in risk appetite are used for the derivation of the cross-market dispersion and correlation, the Haldane and Hall (1991) Kalman filter indicator and the dynamic conditional correlation, while both levels and changes are used respectively in the principal component analysis. 
subject to technical limitations and modelling assumptions, as well as the rather short data sample available, these indicators should be interpreted with caution and taken as indicative but not conclusive evidences on the general trend of the integration process.

Table 1

\section{Summary of integration indicators}

\begin{tabular}{|c|c|c|}
\hline Method & Indicator & Indication of market integration \\
\hline $\begin{array}{l}\text { Cross-market dispersion and } \\
\text { correlation }\end{array}$ & $\begin{array}{l}\text { Hodrick-Prescott filtered } \\
\text { dispersion and correlation }\end{array}$ & $\begin{array}{l}\text { Falling dispersion and high level of } \\
\text { positive correlation imply higher } \\
\text { convergence and larger co- } \\
\text { movement }\end{array}$ \\
\hline Principal component analysis & $\begin{array}{l}\text { The factors derived from the } \\
\text { principal component } \\
\text { analysis }\end{array}$ & $\begin{array}{l}\text { The identification of a small } \\
\text { number of common factors which } \\
\text { are able to explain a high } \\
\text { proportion of total variance among } \\
\text { the risk appetite measures }\end{array}$ \\
\hline $\begin{array}{l}\text { Haldane and Hall (1991) } \\
\text { Kalman filter method }\end{array}$ & $\begin{array}{l}\text { Time-varying } \beta \text { estimated } \\
\text { via Kalman filter }\end{array}$ & $\begin{array}{l}\text { Average } \beta \text { moving towards zero } \\
\text { indicates an increasing sensitivity } \\
\text { to regional influence }\end{array}$ \\
\hline $\begin{array}{l}\text { Dynamic conditional correlation } \\
\text { (DCC) model }\end{array}$ & $\begin{array}{l}\text { Time-varying correlation } \\
\text { estimated from the DCC } \\
\text { model }\end{array}$ & $\begin{array}{l}\text { The higher the correlation, the } \\
\text { larger the co-movement between } \\
\text { markets is }\end{array}$ \\
\hline
\end{tabular}

\section{Estimation results}

\subsection{Integration indicators and financial integration}

The risk appetite measures of investors in the stock markets of the US, the UK, Germany, Japan and HK SAR, as shown in Figure 1, are used to examine the financial integration between these stock markets. This is done by looking at whether investor sentiment (as indicated by these risk appetite measures) spreads over national boundaries.

As a preview, Tables 2 and 3 provide the simple cross-market correlation coefficients between these risk appetite measures in their levels and their changes respectively.

Table 2

\section{Cross-market correlation matrix of risk appetite measures}

(a) Common sample (December 2001 to December 2007)

\begin{tabular}{l|c|c|c|c|c}
\hline & US & UK & Germany & Japan & HK SAR \\
\hline US & 1.000 & 0.002 & $0.272^{\star}$ & -0.155 & -0.103 \\
UK & & 1.000 & $0.277^{\star}$ & 0.102 & -0.047 \\
Germany & & & 1.000 & -0.099 & $-0.279^{\star}$ \\
Japan & & & & 1.000 & $0.385^{\star}$ \\
HK SAR & & & & & 1.000 \\
\hline
\end{tabular}


Table 2 (cont)

Cross-market correlation matrix of risk appetite measures

(b) Pair-wise bilateral sample

\begin{tabular}{l|c|c|c|c|c}
\hline & US & UK & Germany & Japan & HK SAR \\
\hline US & 1.000 & 0.002 & $0.272^{*}$ & -0.155 & -0.103 \\
UK & & 1.000 & $0.219^{\star}$ & 0.068 & 0.188 \\
Germany & & & 1.000 & 0.090 & 0.047 \\
Japan & & & & 1.000 & $0.421^{\star}$ \\
HK SAR & & & & & 1.000 \\
\hline
\end{tabular}

* indicates significance at the $5 \%$ confidence level.

Source: HKMA staff estimates.

Table 2 shows that in their levels, the cross-market correlation coefficients range from -0.28 to 0.42 . Less than half of the cross-market correlation coefficients are statistically different from zero, suggesting a very limited co-movement between these risk appetite measures. The pair of risk appetite measures that has the highest (positive) correlation coefficient is Japan and HK SAR at 0.385 (common sample) and 0.421 (pair-wise bilateral sample), while the correlation coefficients between the US and Germany as well as the UK and Germany are around 0.2 and 0.3 .

Table 3

Cross-market correlation matrix of risk appetite measures

(a) Common sample (January 2002 to December 2007)

\begin{tabular}{l|c|c|c|c|c}
\hline & US & UK & Germany & Japan & HK SAR \\
\hline US & 1.000 & -0.054 & 0.127 & -0.116 & -0.219 \\
UK & & 1.000 & 0.124 & 0.027 & -0.067 \\
Germany & & & 1.000 & -0.177 & -0.207 \\
Japan & & & & 1.000 & 0.128 \\
HK SAR & & & & & 1.000 \\
\hline
\end{tabular}

(b) Pair-wise bilateral sample

\begin{tabular}{l|c|c|c|c|c}
\hline & US & UK & Germany & Japan & HK SAR \\
\hline US & 1.000 & -0.054 & 0.127 & -0.116 & -0.219 \\
UK & & 1.000 & 0.070 & -0.096 & 0.058 \\
Germany & & & 1.000 & -0.166 & -0.188 \\
Japan & & & & 1.000 & 0.093 \\
HK SAR & & & & & 1.000 \\
\hline
\end{tabular}

Source: HKMA staff estimates. 
For the changes in their risk appetites, the co-movement is even smaller. The correlation coefficients range from -0.22 to 0.13 and none of them is statistically different from zero, suggesting that there is little connection between the changes in risk appetite among these economies.

\subsubsection{Cross-market dispersion and correlation}

The cross-market dispersion approach suggests a sense of convergence between the changes in the risk appetite measures if their discrepancy is falling and becoming small. The series of dispersion is filtered using the Hodrick-Prescott (HP) smoothing technique to reveal the long-term trend component of the series.

Figure 2

\section{Cross-market dispersion indicator}

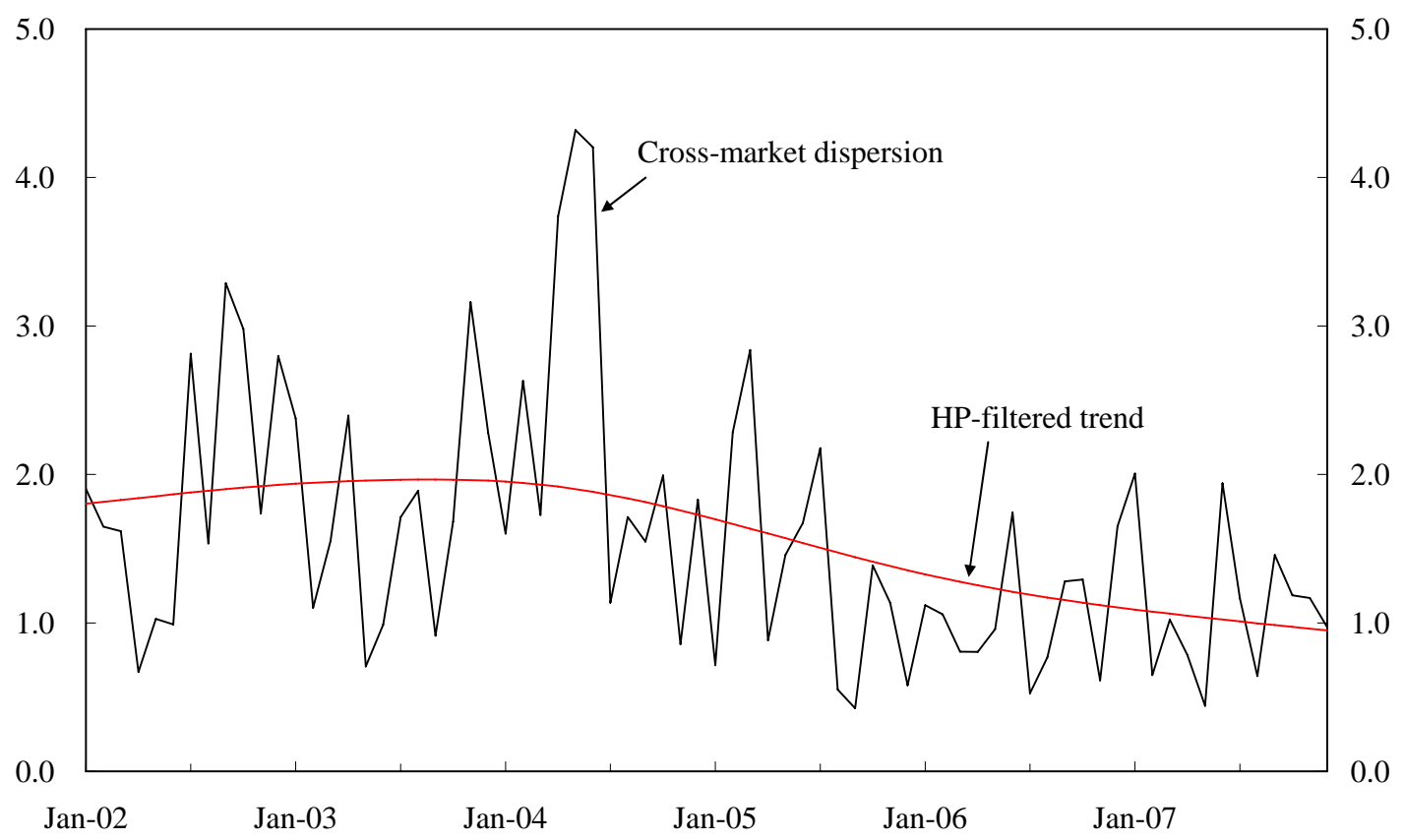

Source: HKMA staff estimates.

Figure 2 shows that the dispersion depicts a gradual decline since mid-2004, suggesting that the variation between the changes in the risk appetite measures has narrowed and some kind of convergence process may have taken place but then stalled since mid-2006. As the dispersion indicator does not provide any indication of co-movement, Figure 3 illustrates the cross-market covariance and correlation. 
Figure 3

\section{Cross-market covariance and correlation of the changes in the risk appetite measures}

(a) Covariance

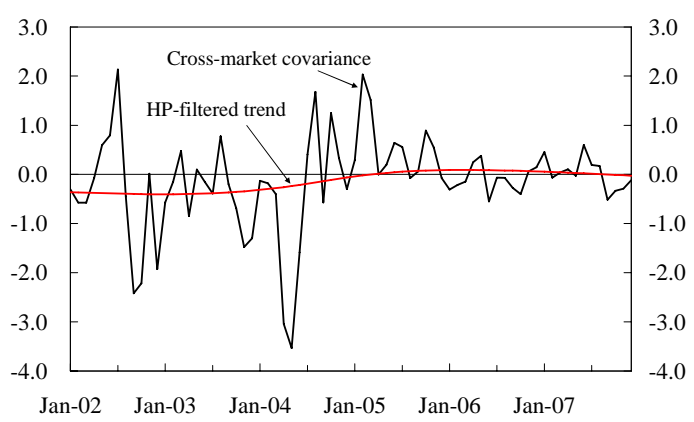

(b) Correlation

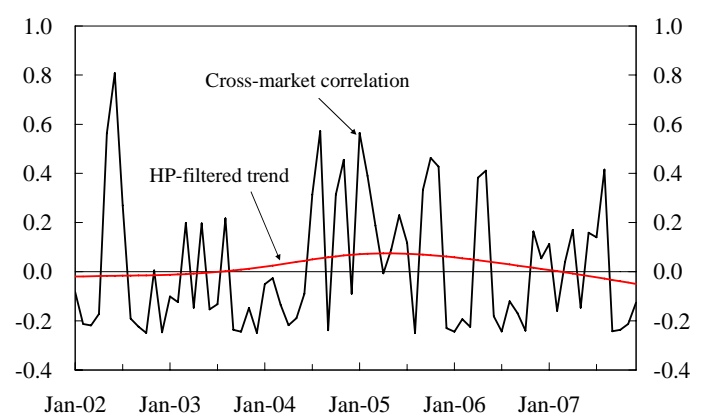

Source: HKMA staff estimates.

The cross-market correlation is defined as the ratio of cross-market covariance to the square of cross-market dispersion. An increase in the correlation can stem either from an increase in the covariance or from a reduction in the dispersion. The cross-market correlation as shown in Figure $3 b$ varies and ranges from -0.25 to 0.81 . From the HP filtered trend line, it is shown that the only significant positive correlation was around late 2004 to early 2006 (which coincides with the gradual decline in the dispersion and the increase in covariance). The cross-market correlation was slightly negative by the end of 2007 . Judging from the crossmarket dispersion and the correlation of the risk appetite measures, even though the dispersion indicator has narrowed, it has stalled since mid-2006. With the low level of crossmarket correlation, the extent of market integration between these five stock markets is not apparent.

\subsubsection{Principal component analysis}

The main objective of principal component analysis (PCA) is to find a small number of factors that can explain most of the variation in the original data series. In many studies, the PCA has been used regularly as one of the tools for the identification of a common factor among different risk measures. For instance, with a set of eight risk premia on corporate bond spreads and swap spreads of the euro area, the US and emerging markets, Coudert and Gex (2006) are able to derive the first component factor which explains $68 \%$ of the common variation of these risk premia. With the risk aversion indicators of the US, the UK and Germany, Tarashev et al. (2003) derive the first principal component which accounts for $80 \%$ of the overall variation in its constituent series. This is interpreted as a common factor driving the dynamics of the three risk aversion indicators. In this section, the risk appetite measures of the five stock markets in both their levels and changes are used in the PCA to extract a list of common factors. ${ }^{14}$ Table 4 reports the PCA result based on the level.

14 The PCA is conducted after mean centering the original risk appetite measures, either in their levels or changes. For the definition of mean centering and other details, please refer to Appendix II. 
Table 4

Principal component analysis result

(based on the levels)

\begin{tabular}{c|c|c}
\hline Eigenvalue & Value & $\begin{array}{c}\text { Proportion of variance } \\
\text { explained }\end{array}$ \\
\hline 1 & 1.424 & 0.285 \\
2 & 1.183 & 0.237 \\
3 & 0.939 & 0.188 \\
4 & 0.789 & 0.158 \\
5 & 0.664 & 0.133 \\
\hline
\end{tabular}

Each eigenvalue represents the proportion of variance accounted for by the corresponding principal component (PC). Normally, the first principal component accounts for as much of the variability in the data as possible, and each succeeding component accounts for as much of the remaining variability as possible.

Source: HKMA staff estimates.

Two criteria are used to choose the number of principal components in this analysis. The Kaiser (1960) criterion keeps those principal components with their corresponding eigenvalues greater than one. The Joliffe (1972) criterion discards those remaining principal components once the percentage of explained variance reaches a certain threshold (for example 80\%). The result shown in Table 4 indicates that the first two principal components, PC1 and PC2, satisfy the Kaiser criterion as their corresponding eigenvalues are greater than one. However, these two PCs account for only $52.2 \%$ of the variability in the data, with the PC1 explaining a mere $28.5 \%$ of the common variation. Based on the Joliffe criterion, it takes a total of four PCs against the five risk appetite measures in order to account for about $87 \%$ of the total variance of these measures. ${ }^{15}$ These findings seem to suggest that there does not exist one common factor that drives these risk appetite measures.

The systematic shift in investors' risk appetite across financial markets can also be assessed by how the changes in the risk appetite measures are correlated. Table 5 reports the PCA result based on the changes in the risk appetite measures in the five economies.

15 If the underlying series are highly correlated, normally it takes only a few component factors to explain a large bulk (for example 80\%) of the total variance, and the first component factor, which is generally interpreted as the common factor of the underlying series, usually constitutes the largest proportion (60\% to $70 \%$ ) of the common variation. 
Table 5

Principal component analysis result

(based on the changes in the risk appetite measures)

\begin{tabular}{c|c|c}
\hline Eigenvalue & Value & $\begin{array}{c}\text { Proportion of variance } \\
\text { explained }\end{array}$ \\
\hline 1 & 1.314 & 0.263 \\
2 & 1.058 & 0.212 \\
3 & 1.036 & 0.207 \\
4 & 0.827 & 0.165 \\
5 & 0.765 & 0.153 \\
\hline
\end{tabular}

Each eigenvalue represents the proportion of variance accounted for by the corresponding principal component (PC). Normally, the first principal component accounts for as much of the variability in the data as possible, and each succeeding component accounts for as much of the remaining variability as possible.

Source: HKMA staff estimates.

Based on the Kaiser criterion, the first three PCs are chosen as their corresponding eigenvalues are greater than one. Nevertheless, these three PCs account for less than $70 \%$ of the total variance, with the first PC explaining only $26.3 \%$ of the variability of the original data. In terms of the Joliffe criterion, a total of four PCs is needed to reach the threshold of $80 \%$ explained variability. Therefore, similar to the results based on the level measure, there does not exist any significant factor driving the changes in the risk appetites in these economies.

From the above PCA, the dynamics of the risk appetite measures, either in levels or changes, are likely to be driven by more than one factor. As a result, the five stock markets together are hardly integrated. ${ }^{16}$

\subsubsection{Haldane and Hall (1991) Kalman filter method}

For this indicator, we take the changes in the US's risk appetite measure as the dominant source. Based on the signal equation of Equation (A10) in Appendix II, the estimated $\beta$ measures the sensitivity of an individual economy's risk appetite changes to that in the US relative to that in another economy. An economy's risk appetite changes which are more sensitive to the changes in the risk appetite in the US will show $\beta$ s trending close to one, $a$ sign interpreted as a convergence (or integration) with the US market. A tendency for $\beta$ to approach towards zero suggests a convergence with another market. Negative values of $\beta$ or $\beta \mathrm{s}$ greater than one suggest that the market drifts away from the US and the other

16 It is noted that Tarashev et al. (2003) obtain the first principal component which accounts for $80 \%$ of the overall variation in its three risk aversion indicators of the US, the UK and Germany. To examine whether this is still true in recent years, we also apply the PCA on the risk appetites of these three economies using our risk appetite measures. The new PCA results show that the first principal component only accounts for $44 \%$ of the common variation in the three risk appetite measures in their levels and $38 \%$ in their changes respectively. The new results suggest that there is only a weak common factor driving the dynamics of the risk appetite measures in these three economies. 
markets. Figure 4 shows the patterns of the $\beta$ estimates for each of the market other than the US.

Figure 4

\section{Haldane and Hall sensitivity indicator $(\beta)$}

(based on the changes in the risk appetite measures)

HK SAR

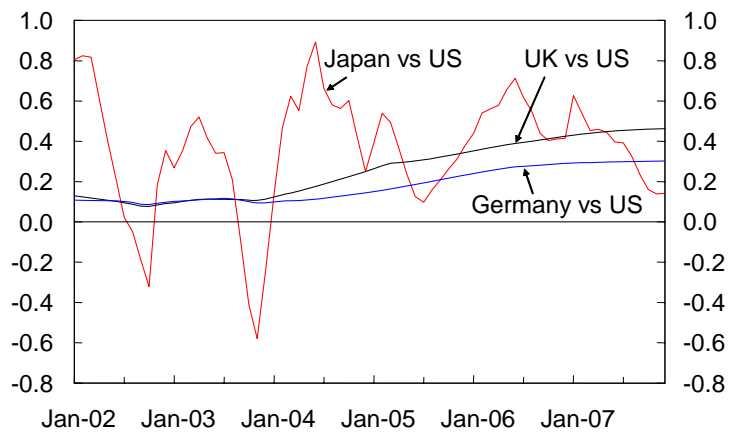

UK

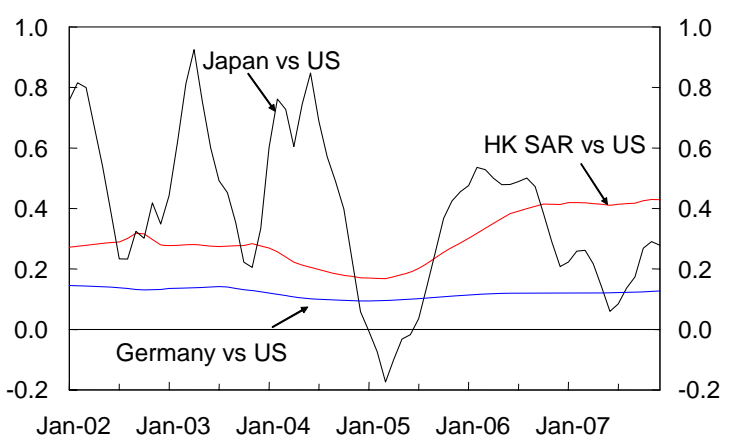

Japan

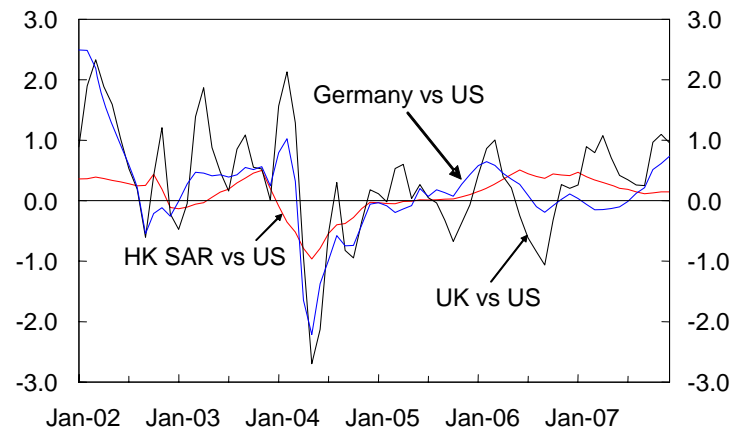

Germany

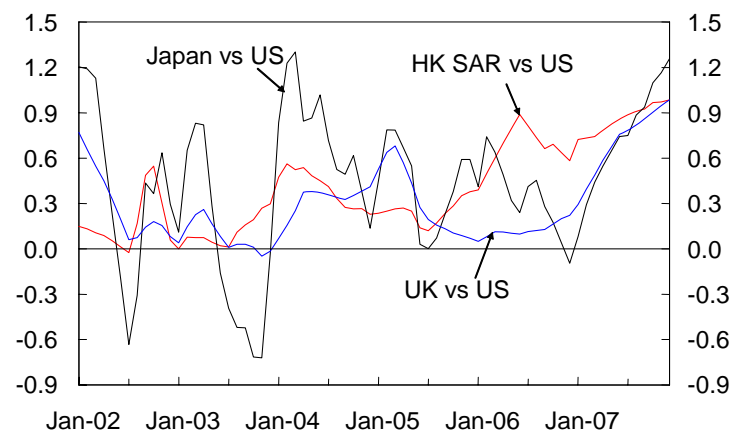

A tendency for $\beta$ to approach towards one suggests a convergence with the US's risk appetite change.

Source: HKMA staff estimates.

From Figure 4, in the case of HK SAR, its $\beta$ estimates are found to be more sensitive to the changes in the risk appetite measures of the UK and Germany, as the respective $\beta$ estimates were closer to zero (around 0.1) than one in the period between January 2002 and September 2003. They began to trend upward in 2004, suggesting an increase in the sensitivity of the changes in HK SAR's risk appetite to the US's changes. The $\beta$ estimates varied with respect to Japan and the US. But since 2007, the sensitivity to the change in Japanese risk appetite had increased. Such results appear to suggest an increased influence from Japan and a gradual decline in the sensitivity with the UK and Germany. The situation is very much the same in Japan, where the influence from the UK and Germany had completely been dominated by that from the US, while the sensitivity to that of HK SAR had also increased since 2007. For the UK, the pattern of its $\beta$ estimates indicates that it had been consistently more sensitive to that from Germany than from the US. While its sensitivity to that of HK SAR had declined, influence from Japan had picked up. Finally, for Germany, its $\beta$ estimates for the past two years pointed to an increased sensitivity to that of the US, as the $\beta$ estimates trended towards one. The overall results from the Haldane and Hall 
approach suggest some sorts of market segmentation between the five stock markets. While the risk appetite measures of HK SAR and Japan in their changes are very sensitive to each other, the influence of the US on them has been increasing. The German's risk appetite changes are highly influenced by that of the US, while that of the UK is closer to the German's. As the convergence processes from these four markets (with the US as the major source of influence) did not point to any particular market as a dominant factor, these five markets are not highly integrated.

\subsubsection{Dynamic conditional correlation (DCC)}

A GARCH(1,1)-DCC model using a two-step estimation procedure as outlined in Appendix II is estimated with monthly changes in their risk appetite measures. Basically, higher and positive correlation between the changes in the risk appetite measures implies higher comovement and greater integration between the markets. Table 6 highlights the average pairwise dynamic conditional correlation between the changes in these risk appetite measures.

Table 6

Average pair-wise conditional correlation

(based on the changes in the risk appetite measures)

\begin{tabular}{l|c|c|c|c|c}
\hline & US & UK & Germany & Japan & HK SAR \\
\hline US & 1.000 & -0.078 & 0.140 & -0.030 & -0.100 \\
UK & & 1.000 & 0.138 & -0.058 & -0.076 \\
Germany & & & 1.000 & -0.111 & -0.181 \\
Japan & & & & 1.000 & 0.167 \\
HK SAR & & & & & 1.000 \\
\hline
\end{tabular}

Source: HKMA staff estimates.

The table shows that, in general, the co-movements between the changes in the risk appetite measures are not high with their conditional correlations ranging from -0.030 to 0.167 only. Of the ten pair-wise risk appetite measures, only three pairs are positively correlated. The result is similar to that reported in Table 2 based on simple correlation. The three positivelycorrelated pairs are HK SAR - Japan, US - Germany and UK - Germany. Again, the results coincide with the findings from the Haldane and Hall approach which show that the changes in HK SAR risk appetite is highly sensitive to that of Japan, the German market is more influenced by the US market and the change in the UK risk appetite is closer to that of Germany. Figure 5 shows the time-varying conditional correlations between the five risk appetite measures. 
Figure 5

\section{DCCs of risk appetite measures}

(based on the changes in the risk appetite measures)

HK SAR

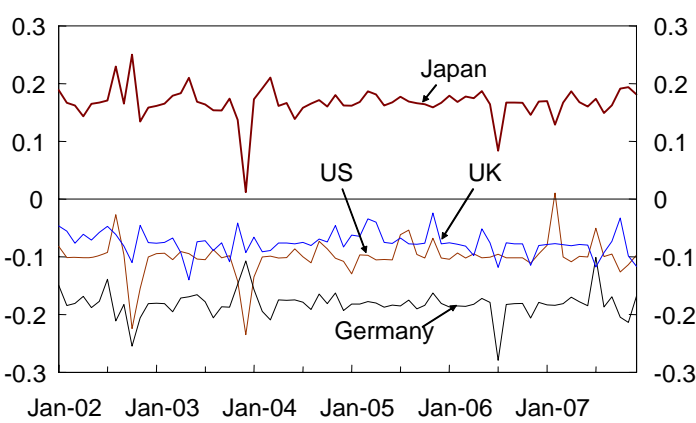

UK

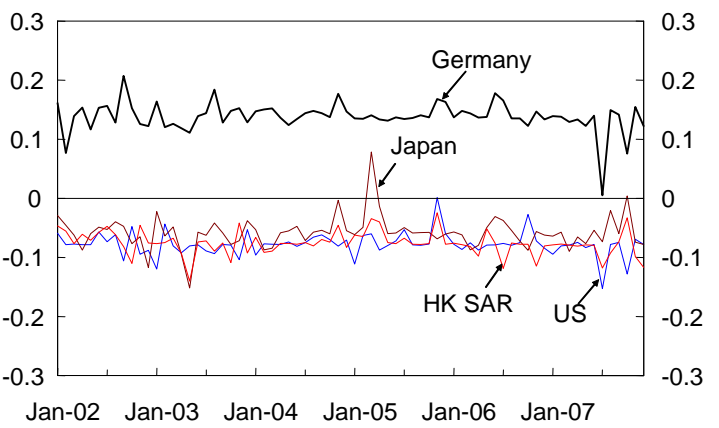

Japan

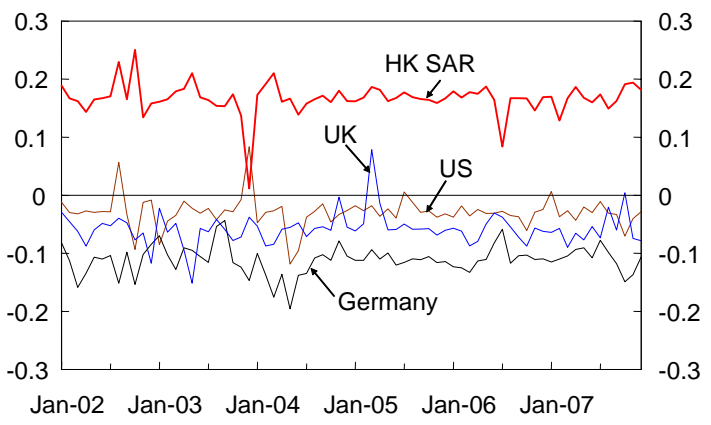

Germany

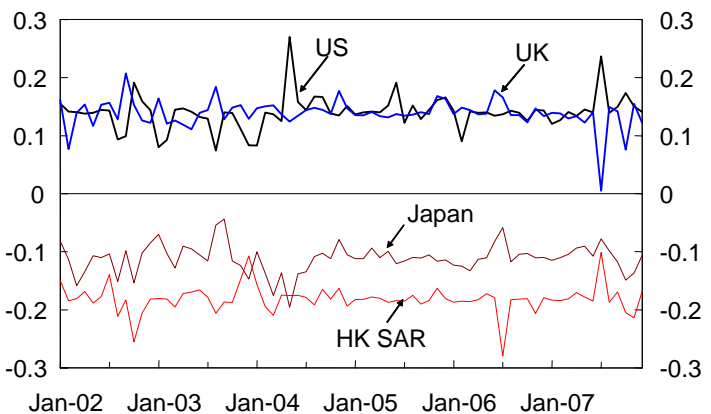

US

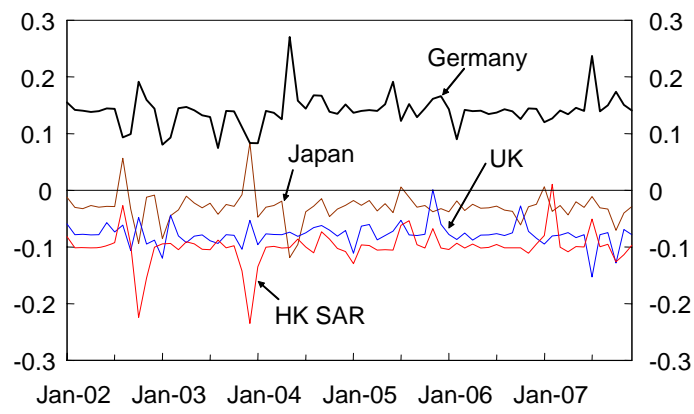

Source: HKMA staff estimates.

From the graphs in Figure 5, the conditional correlations are in general smooth with only occasional spikes. For those economies with their changes in the risk appetite positively correlated, their conditional correlations are low and less than 0.3. Given that the conditional correlations are at a low level with only three pairs of the risk appetite measures are positively correlated, and their conditional correlations are not even increasing, the five financial markets do not appear to be integrated.

Overall, our four integration indicators suggest a limited degree of integration between the stock markets in the US, the UK, Germany, Japan and HK SAR. The only encouraging sign is from the dispersion indicator which shows a gradual declining trend in the discrepancy but the process appears to be stalled since mid-2006. Even if the risk appetites in these markets are not equal, it is still possible that a shift in investors' risk appetite in one particular 
economy has an influence on other economies' financial markets because of the participation of international investors in their domestic markets. The next section investigates the interdependence between financial markets arising from changes in investors' risk appetite.

\subsection{Financial market interdependence}

Apart from examining the issue of financial integration, the risk appetites in the five economies are also used to assess the interdependence between financial markets. This is done by examining the co-movement between these risk appetite measures and the performance in the stock and bond markets using the dynamic conditional correlation method (DCC). In the analysis that follows, for the stock market the DCC is conducted in terms of the changes in the risk appetite measures and the stock market returns. In general, one would expect a positive relationship (positive DCC) between the changes in the risk appetite measures and the stock market returns. Hence, an increase (decrease) in investors' risk appetite is associated with a rise (fall) in the stock market. For the bond market, the DCC is related to the risk appetite levels and the benchmark bond yields of different maturities. The "flight-to-quality" phenomenon of the bond market suggests a positive relationship (positive DCC) between the risk appetite levels and the bond yields. For instance, if investors become more risk averse (their risk appetites fall), they seek a "safe haven" by investing in the bond markets, thus bidding up bond prices and leading to a fall in bond yields. In addition to the intra-economy co-movement between an individual economy's risk appetite measure and its stock and bond markets, we are also interested in the inter-economy spillover effect across another economy's stock and bond markets. Such an analysis should provide insight on the possible contagion risk arising from a systemic shift in investors' risk appetite. We must emphasise that the analyses are not examining the causal relationship or the transmission mechanism between risk appetite changes (level) and stock (bond) market performance, but simply looking into their co-movement and correlation.

Table 7 shows the average conditional correlations between the changes in the risk appetite measures and the monthly return of the stock market benchmark indices. ${ }^{17}$

Table 7

Average conditional correlation between the changes in the risk appetite and the stock market return

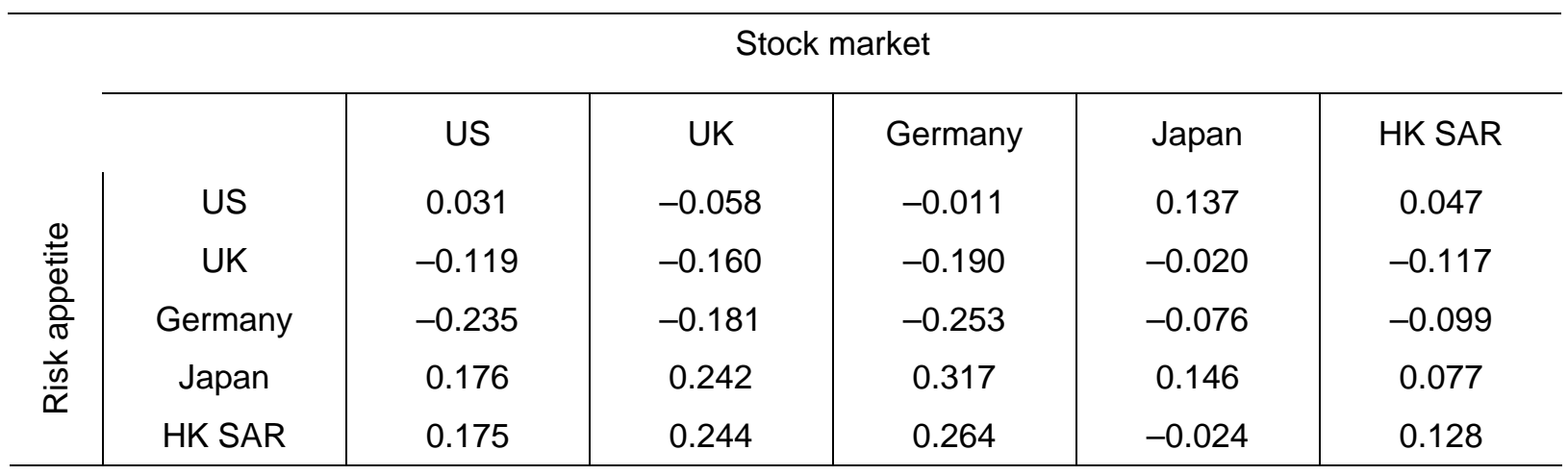

Source: HKMA staff estimates.

17 The monthly return of the stock market is calculated as the log difference of the stock market benchmark index. 
The diagonal elements in the table show the intra-economy conditional correlation between the changes in the risk appetite measures and the stock market return. It is shown that for the US, Japan and HK SAR, the intra-economy conditional correlations are positive, while for the UK and Germany, they are negative. Thus, the conventional intuition that an increase (decrease) in investors' risk appetite is associated with a rise (fall) in the stock market can be applied to the stock markets in the US, Japan and HK SAR, but not to those in the UK and Germany.

The results from inter-economy conditional correlations (the off-diagonal elements) are more revealing. It is shown that the changes in the risk appetite in Japan and HK SAR are positively related to the stock market returns of other economies (with the exception of HK SAR's risk appetite changes and Japan's stock market return performance). Hence, a drop in investors' risk appetite in either Japan or HK SAR will be associated with falls in other economies' stock markets. Changes in the US's risk appetite are also positively related to the stock market returns in Japan and HK SAR, while they are negatively related to that in the UK and Germany. Thus, there may be possible contagion effect between the changes in the risk appetites in the US, Japan and HK SAR and the stock market returns, given that they are positively interdependent. On the contrary, risk appetite changes in the UK and Germany are negatively associated with other economies' stock market return. Figure 6 shows the timevarying conditional correlations between individual economy's risk appetite and their stock market performance.

\section{Figure 6}

\section{DCCs of individual economy's changes in the risk appetite and the stock market return}

HK SAR

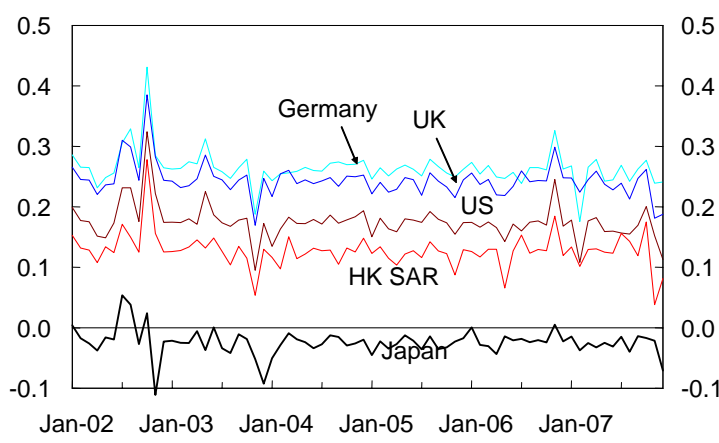

UK

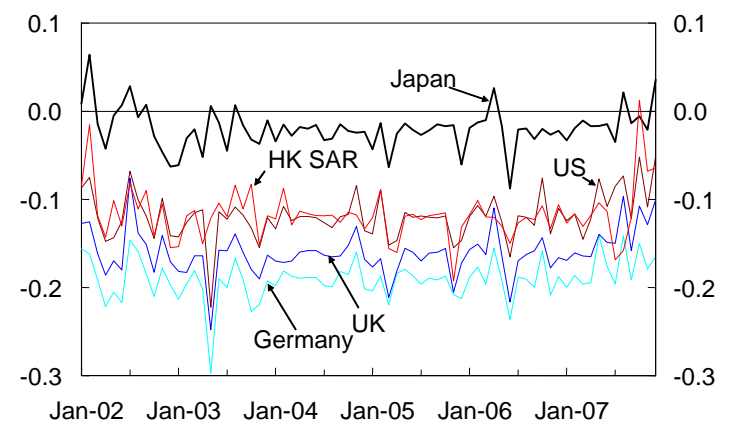

Japan

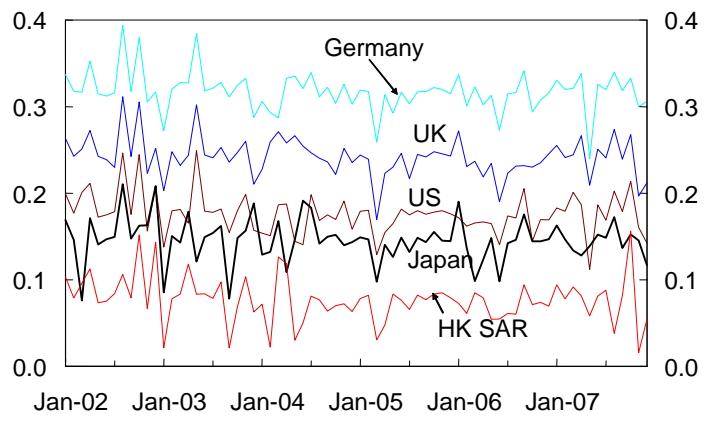

Germany

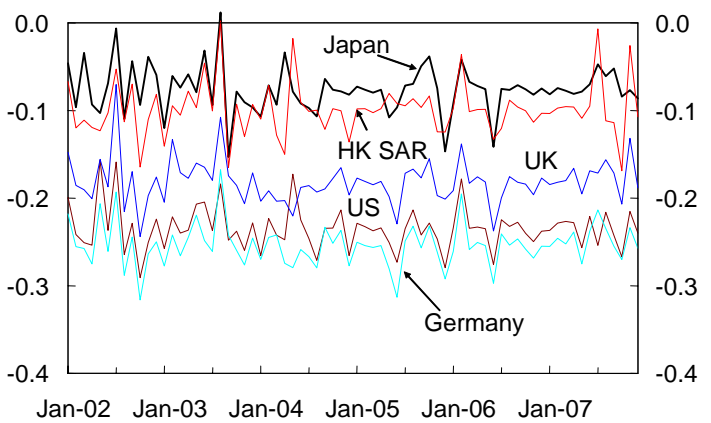




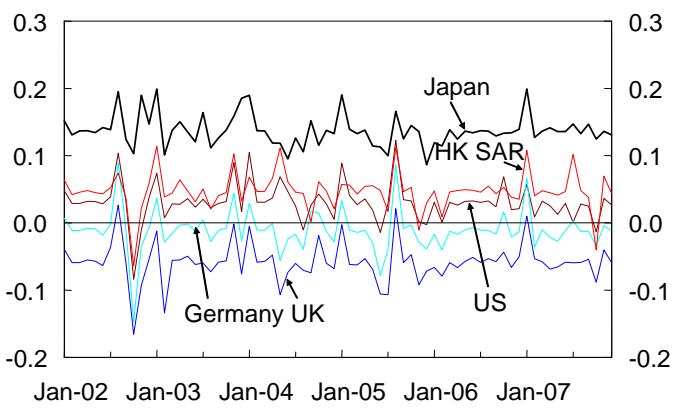

Source: HKMA staff estimates.

The graphs in Figure 6 show that the conditional correlations vary a lot but in general move in a tight range with occasional spikes. For those positive conditional correlations, they are generally low and less than 0.4. There is no clear indication of particular trend or pattern in the conditional correlations.

To assess the interdependence in the bond market, we examine the interaction between the risk appetite measures and the yields of 3-month as well as 10-year government bonds respectively. ${ }^{18}$ The results may reveal whether the "flight-to-quality" phenomena from stock to bond markets are apparent in these five economies. Table 8 provides the average conditional correlations between the risk appetite measures and the government bond yields.

\section{Table 8}

\section{Average conditional correlation between risk appetite} measures and government bond yields

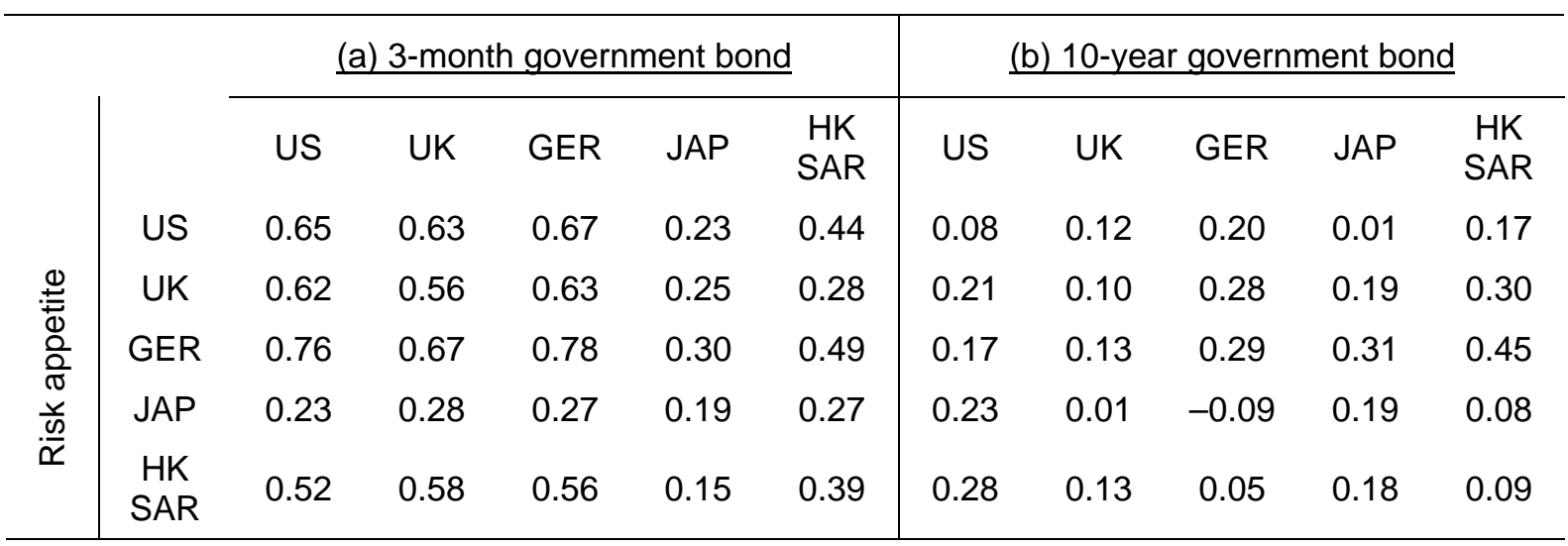

The abbreviations in the table are as follows: GER for Germany and JAP for Japan.

Source: HKMA staff estimates.

18 All yield data are the yields of the benchmark government bonds and are taken from CEIC. Note that for HK SAR, the 3-month government bill yields are those of the 3-month Exchange Fund Bills, while the 10-year government bond yields are those of the 10-year Exchange Fund Notes. For Germany, the 3-month yield is the 3-month EURIBOR. 
The conditional correlations as shown in Table 8 are mostly positive regardless of the maturity. The conditional corrections between the risk appetite measures and the 3-month yields (ranging from 0.15 to 0.78 ) are, in general, higher than those between the risk appetite measures and the 10-year yields (from -0.09 to 0.45 ). This suggests that the relationship between the risk appetite measure and the bond yield is stronger for bonds with a shorter maturity than those with a longer maturity. The diagonal elements under the two maturities show the intra-economy conditional correlation between an economy's risk appetite and its corresponding government bond yields. It is shown that the intra-economy conditional correlations are all positive. Such a positive relationship suggests that, to a certain extent, there exists a "flight-to-quality" phenomenon in the bond market of these five economies. As investors become more risk averse (their risk appetites fall), they seek a "safe haven" by investing in the bond markets, thus bidding up bond prices and leading to a fall in bond yields.

The results from inter-economy conditional correlations are also consistent with the "flight-toquality" phenomenon as all but one off-diagonal conditional correlation are positive. The only exception is the conditional correlation between Japan's risk appetite and German's 10-year bond yield which is negative but at a low level. The degree of positive association between the risk appetite level and the bond yields in the economies are also different to each others. For instance, the conditional correlations between the risk appetite measures in the US, the UK and Germany and the 3-month bond yields (from 0.23 to 0.78 ) are much higher than the correlations between the risk appetite measures of their Asia counterparts and the 3-month bond yields. Meanwhile, between the two Asian economies, the conditional correlations between the risk appetite measure in HK SAR and the 3-month bond yields (from 0.15 to 0.58) are higher than the risk appetite measure in Japan and the 3-month yields (from 0.19 to 0.28). The results highlight the "flight-to-quality" phenomenon in the bond market of the five economies when investors in a particular economy are becoming risk averse. The timevarying conditional correlations between individual economy's risk appetite measures and the bond market performance are given in Figures 7 and 8 .

Figure 7

\section{DCCs of individual economy's risk appetite measures and 3-month bond yields}

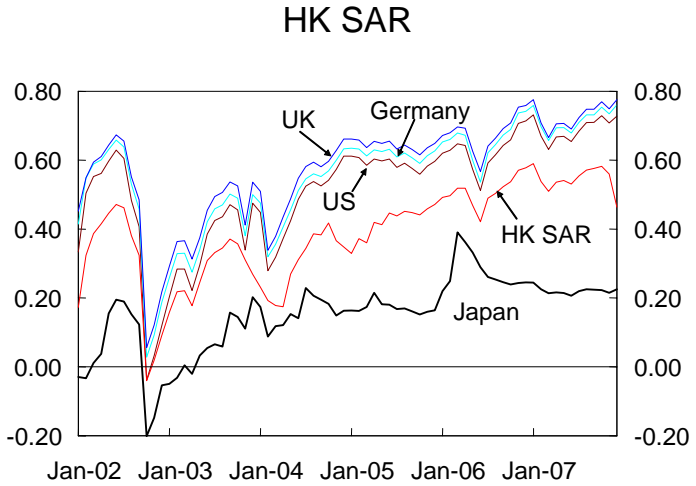

Japan

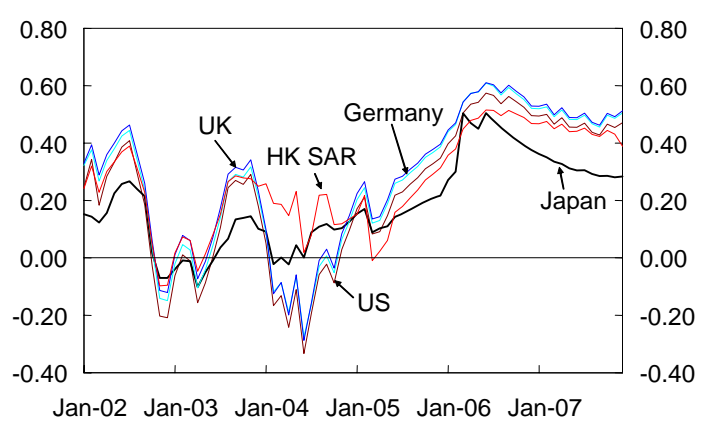


UK

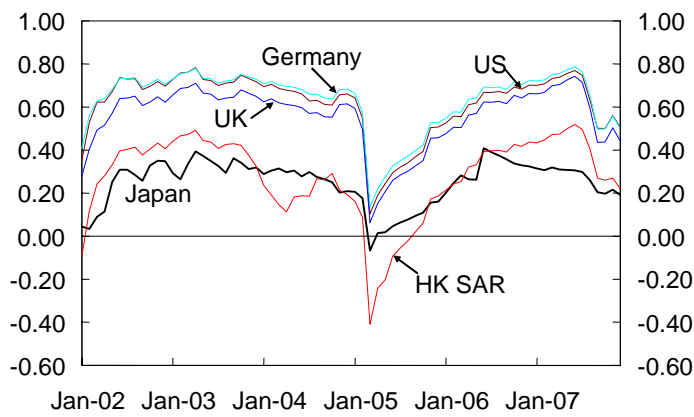

Germany

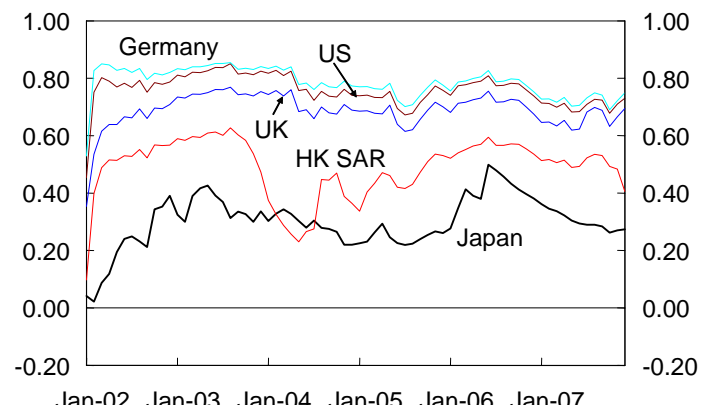

US

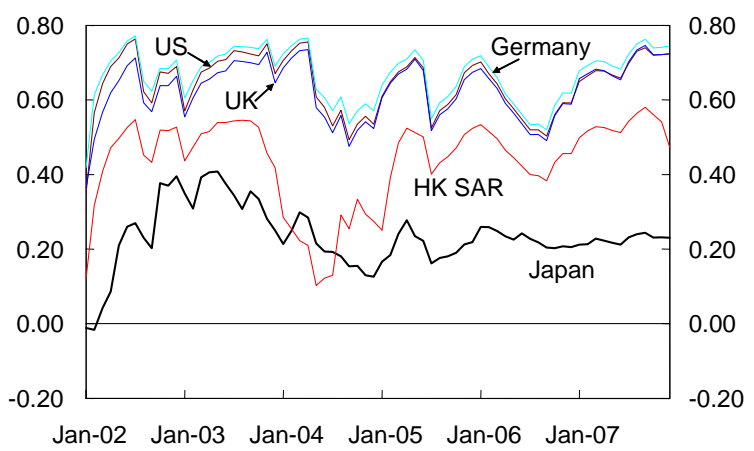

Source: HKMA staff estimates.

The graphs in Figure 7 show that the conditional correlations between the risk appetite measures and the 3-month bond yields vary and in a few occasions they turn into a negative relationship. Such a negative correlation is the most obvious between the risk appetite measure in Japan and the 3-month bond yields during mid-2002 to mid-2003 and the whole year of 2004. Note that during these two periods, the risk appetite measures in Japan were at a low level (see Figure 1b), which was associated with higher 3-month bond yields (lower bond prices) in the five economies, suggesting a possible contagion effect for bonds with a short maturity when Japanese investors became risk averse. Nonetheless, the conditional correlations are mostly positive over the study period and many of them were at a high level (above 0.5) at the end of 2007.

Figure 8

\section{DCCs of individual economy's risk appetite measures and 10-year bond yields}

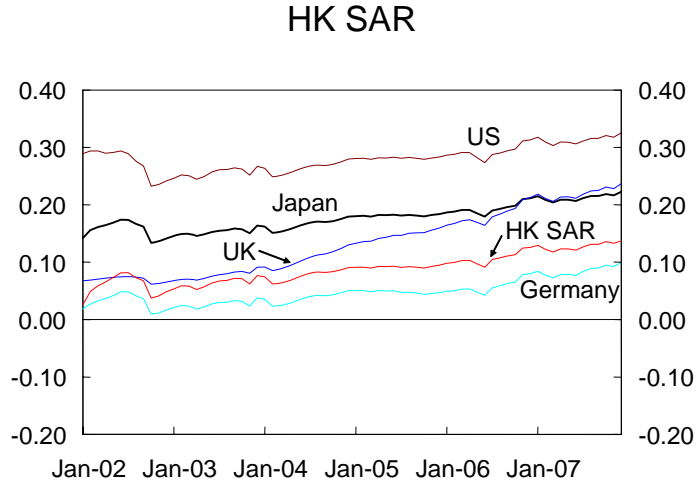

Japan

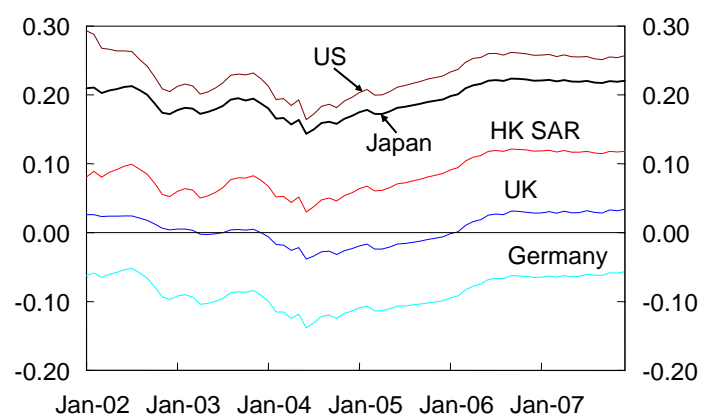


UK

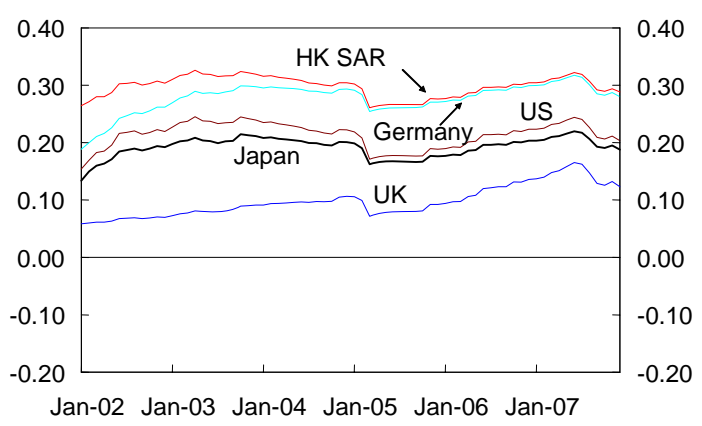

Germany

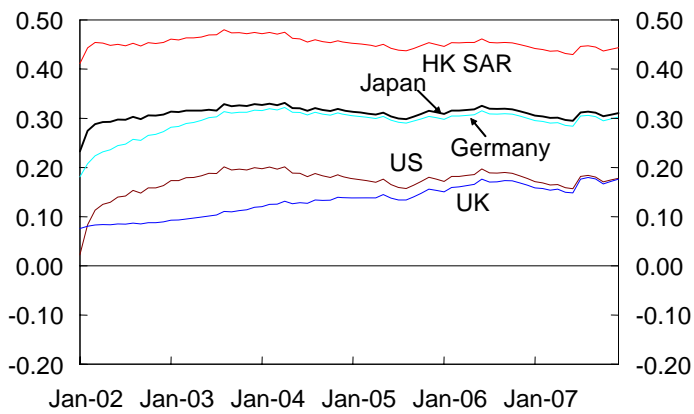

US

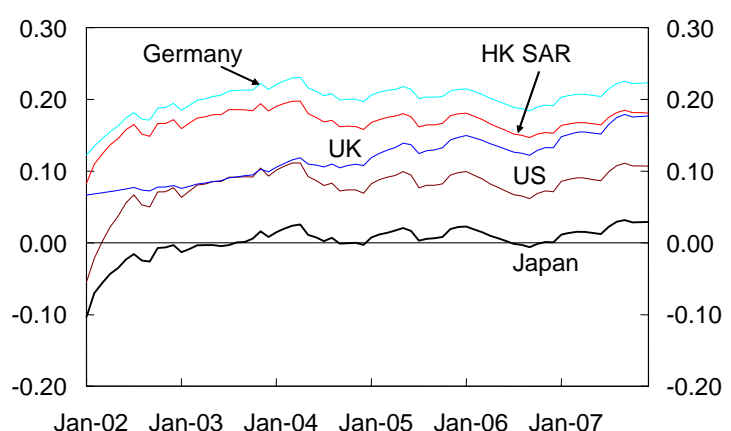

Source: HKMA staff estimates.

The conditional correlations between the risk appetite measures and the 10-year bond yields in Figure 8 are very smooth. For the risk appetite measures in the US and HK SAR, their correlation with other economies' 10-year bond yields were trending upwards, suggesting an increasing relationship between the two. The correlations between Japan's risk appetite measure and 10-year bond yields also increased but have levelled off since early 2006. For the UK and Germany, the conditional correlations between their risk appetite measures and the bond yields were also at a relatively high level, suggesting evidence of "flight-to-quality" due to the stock market turmoil near the end of 2007.

\section{Summary and Conclusion}

This study extends the use of investors' risk appetites in central banks' monitoring work in two aspects, namely financial integration and cross-border financial market interdependence. Various integration indicators are constructed to gauge the relationship between the risk appetites derived for five economies: the US, the UK, Germany, Japan and HK SAR. Furthermore, we examine the degree of co-movement between the risk appetite measures and the stock and bond market performances in these economies. The evolution of such comovements provides some insights to policy makers on the interdependence between stock and bond markets in these economies, which may give rise to possible contagion risk during financial market turmoil.

Table 9 provides a summary on the financial market integration aspect from the indicators derived using the risk appetite measures. 
Table 9

Summary of financial market integration

\begin{tabular}{|c|c|c|}
\hline Method & Indication of market integration & Result \\
\hline $\begin{array}{l}\text { Cross-market } \\
\text { dispersion and } \\
\text { correlation }\end{array}$ & $\begin{array}{l}\text { Falling dispersion and high level } \\
\text { of positive correlation imply higher } \\
\text { convergence and greater co- } \\
\text { movement }\end{array}$ & $\begin{array}{l}\text { Even though the dispersion indicator } \\
\text { has narrowed, it has stalled since mid- } \\
2006 \text {. The degree of positive cross- } \\
\text { market correlation is also at a low level }\end{array}$ \\
\hline $\begin{array}{l}\text { Principal component } \\
\text { analysis (PCA) }\end{array}$ & $\begin{array}{l}\text { The identification of a small } \\
\text { number of factors which are able } \\
\text { to explain a high proportion of } \\
\text { total variance among the risk } \\
\text { appetite measures }\end{array}$ & $\begin{array}{l}\text { The PCA results (based on levels or } \\
\text { their changes) are less than } \\
\text { satisfactory and we fail to obtain a first } \\
\text { component factor that can account for } \\
\text { a large proportion of the common } \\
\text { variation between the risk appetite } \\
\text { measures }\end{array}$ \\
\hline $\begin{array}{l}\text { Haldane and Hall } \\
\text { (1991) Kalman filter } \\
\text { method }\end{array}$ & $\begin{array}{l}\text { Average } \beta \text { moving towards zero } \\
\text { indicates an increasing sensitivity } \\
\text { to regional influence }\end{array}$ & $\begin{array}{l}\text { The overall results suggest some } \\
\text { degrees of market segmentation } \\
\text { between the five stock markets, and no } \\
\text { particular market acts as a dominant } \\
\text { factor in influencing the risk appetite of } \\
\text { another economy }\end{array}$ \\
\hline $\begin{array}{l}\text { Dynamic conditional } \\
\text { correlation (DCC) } \\
\text { model }\end{array}$ & $\begin{array}{l}\text { The higher the (positive) } \\
\text { correlation, the larger the co- } \\
\text { movement between markets is }\end{array}$ & $\begin{array}{l}\text { For those positive conditional } \\
\text { correlations, they are generally low and } \\
\text { less than } 0.4 \text {. There is no clear } \\
\text { indication of particular trend or pattern } \\
\text { in the conditional correlations }\end{array}$ \\
\hline
\end{tabular}

From Table 9, despite the different focus of each of these indicators, the picture that emerges from the empirical results is quite uniform. In terms of co-movement, both the crossmarket correlation and the DCC point to a low level of correlation between the changes in the risk appetite measures. While the dispersion has narrowed, the process has halted since mid-2006. Results from the Haldane and Hall approach suggest that there is no indication of a particular economy whose changes in risk appetite play a dominant role in influencing other economies' risk appetite changes. Finally, as the first component factor derived from the PCA is unable to account for a high proportion of the common variation among the risk appetite measures (either in their levels or changes), it is difficult to conclude that a common factor is driving the dynamics of these risk appetite measures. There may only be a weak integration between the five financial markets and our integration indicators suggest some degrees of market segmentation in the process. For instance, the risk appetite measures of Japan and HK SAR, either in their levels or changes, are negatively correlated with the first common factor from the PCA, when other economies' risk appetite measures are positively related to that common factor. Furthermore, results from the Haldane and Hall approach also indicate that the changes in risk appetite measures of HK SAR and Japan are very sensitive to each other. Meanwhile, the risk appetite in Germany is highly influenced by that of the US, while that of the UK is closer to the German risk appetite measure.

While there is limited financial integration among the five stock markets, however, the risk appetite measures reveal the interdependence between shifts in the risk appetite measures and financial market performance. For the stock market, the results from the dynamic conditional correction indicate that there may be possible contagion risk between changes in the risk appetites in the US, Japan and HK SAR and the stock market performance, given that they are positively interdependent. For the bond market, with mainly positive correlations between the risk appetite measures and the 3-month or 10-year government bond yields, the "flight-to-quality" phenomenon is apparent in the bond market of the five economies. 
Given the information contained in investors' risk appetite measures and the evidence of interdependence in the stock markets, policy makers should continue monitoring their movements for financial stability reasons. However, as investors' risk appetite is not directly observable in the market and the development of the methodology for the derivation of investors' risk appetite is still an on-going process, the application of the risk appetite measure in central banks' monitoring framework should be used with caution. 


\section{Appendix I: \\ Methodology for the derivation of the risk appetite measures}

This Appendix provides a brief description of the Gai and Vause (2006) methodology for the derivation of the risk appetite measures. As mentioned in the main text, the derivation of the investor's risk appetite requires the estimation of the option-implied risk-neutral probability density (RND) function and the subjective history implied density function. The following sections describe the methods for finding these two functions.

\section{Al.1 Estimating the RND by fitting the two-lognormal mixture distribution}

The prices of European call and put options at time $t$ can be written as the discounted sums of expected future payoffs:

$$
\begin{aligned}
& c(X, \tau)=e^{-r \tau} \int_{X}^{\infty} f *\left(S_{T}\right)\left(S_{T}-X\right) d S_{T} \\
& p(X, \tau)=e^{-r \tau} \int_{0}^{X} f *\left(S_{T}\right)\left(X-S_{T}\right) d S_{T}
\end{aligned}
$$

where $c(X, \tau)$ and $p(X, \tau)$ are the call and put prices respectively. The option prices are functions of the strike price $(X)$, the time to maturity $(\tau)$, the asset price at the expiry $\left(S_{T}\right)$, the risk-free interest rate $(r)$ and the density function of the asset price as at expiry $\left(f *\left(S_{T}\right)\right)$. Assuming that the density function is a two-lognormal mixture, $f *\left(S_{T}\right)$ at time $t$ can then be expressed as:

$$
f\left(S_{T}\right)=\sum_{i=1}^{2} \theta_{i} L\left(a_{i}, b_{i} ; S_{T}\right)
$$

where:

$$
\begin{aligned}
& a_{i}=\ln S_{t}+\left(\mu_{i}-\frac{\sigma_{i}^{2}}{2}\right) \tau \\
& b_{i}=\sigma_{i} \sqrt{\tau}
\end{aligned}
$$

$L\left(a_{i}, b_{i} ; S_{T}\right)$ is the $i$-th lognormal density function with parameters $a_{i}$ and $b_{i}, \theta_{i}$ is the weight of the $i$-th density in the mixture and the mixtures are summed to unity, $\mu_{i}$ and $\sigma_{i}$ are the mean and volatility (in standard deviation) of asset return respectively. At any time $t$, five parameters $\left(a_{1}, b_{1}, a_{2}, b_{2}, \theta_{1}\right)$ in the two-lognormal density functions are estimated by solving the following minimisation problem:

$$
\underset{a_{i}, b_{1}, a_{2}, b_{2}, \theta_{1}}{\operatorname{Min}}\left\{\sum_{n=1}^{N}\left[c(X, \tau)-c_{o b s}\right]^{2}+\sum_{n=1}^{N}\left[p(X, \tau)-p_{o b s}\right]^{2}\right\}
$$


where $N$ is the number of possible expiry asset price, $c_{o b s}$ and $p_{o b s}$ are the observed call and put prices at $t$ respectively. By substituting the estimated parameters from (A6) into (A3), the probability density at different prices can be calculated accordingly. ${ }^{19}$

\section{Al.2 Estimating the subjective probability by the threshold GARCH model}

The subjective history implied probability is estimated by the threshold GARCH model of the underlying stock market index return $\left(r_{t}\right)^{20}$ :

$r_{t}=\beta+\varepsilon_{t}$

$\sigma_{t}^{2}=\phi_{1}+\phi_{2} \varepsilon_{t-1}^{2}+\phi_{3} \varepsilon_{t-1}^{2} D_{t-1}+\phi_{4} \sigma_{t-1}^{2}$

$D_{t}=1$ if $\varepsilon_{t}<0$ and 0 otherwise

where $r_{t}$ is the return of the stock market index at $t, \sigma_{t}$ is the volatility of the return which follows the threshold GARCH $(1,1)$ model. To derive the risk appetite measure at time $t$, we need to obtain the forecast of the subjective probability as at $t+1$. For this purpose, we first estimate the GARCH model by the data up to time $t$. In order to have monthly estimates of the mean return and the variance, and in view of the possible structural change in the data series, the GARCH estimation is based on a 10-year rolling sample. The expected return and variance of the return as at $t+1$ can then be forecasted by (A7) and (A8). Plugging these forecasts into the lognormal density function of asset price gives the subjective probability of the stock market index. ${ }^{21}$

19 Note that $L$ is the standard lognormal density function: $L_{i}=\frac{e^{\frac{-\left(\ln S_{T}-a_{i}\right)^{2}}{2 b_{i}^{2}}}}{S_{T} b_{i} \sqrt{2 \pi}}$

20 Different specifications for GARCH model, such as $A R(1)$ and $A R(2)$ for the mean equation, GARCH $(1,2)$ and $\operatorname{GARCH}(2,2)$ for the GARCH equation have been tried and they make no or insignificant difference on the resulting density. Therefore, the simplest one $(\operatorname{GARCH}(1,1))$ is chosen for the sake of convenience.

21 As the underlying stock market index is assumed to be lognormally distributed, its log-return should be normally distributed. Therefore the normally distributed $\mathrm{GARCH}$-implied return and the corresponding variance can be directly plugged into the lognormal distribution function. 


\section{Appendix II: \\ Indicators of financial market integration: Methodology and interpretation}

This Appendix provides in details the methodologies of constructing the different indicators for assessing financial market integration and their interpretation. All integration indicators are derived based on changes in the risk appetite measures, with the principal component analysis also considering the level of the risk appetite measures. The sample period for the estimation of these integration indicators is from December 2001 to December 2007.

\section{i. Cross-market dispersion and correlation}

The idea behind the cross-market dispersion approach introduced by Solnik and Roulet (2000) is simple and intuitive. This can be used as an alternative to the time-series approach to estimating the level of correlation of financial markets. Following the law of one price, identical or comparable assets across different economies should generate the same return. If there is a large discrepancy in financial market returns across economies, as measured by the cross-market dispersion indicator, it will imply that the financial markets are not fully integrated. In this measure, a low level of dispersion implies a higher degree of market integration and vice versa. The method has been applied by Adjaoute and Danthine (2003) and Baele et al. (2004) to assess the equity market integration in Europe. While the method is commonly used on financial asset returns, we apply the method on the changes in the risk appetite measures.

To construct this measure, for $N$ economies, the monthly change in the risk appetite measure of economy $i$ at month $t\left(R_{t}^{i}\right)$ is specified as:

$R_{t}^{i}=R A_{t}^{i}-R A_{t-1}^{i}$

where $R A_{t}^{i}$ is the risk appetite measure of economy $i$ at month $t$. The cross-market dispersion indicator is defined as:

Cross-market dispersion at month $t=\sqrt{\frac{1}{N} \sum_{i=1}^{N}\left(R_{t}^{i}\right)^{2}}$

In addition to the cross-market dispersion indicator, the cross-market correlation is also derived. First, we obtain the cross-market covariance, which is defined as:

Cross-market covariance at month $t=\frac{1}{N^{2}-N} \sum_{i=1}^{N} \sum_{\substack{j=1 \\ j \neq i}}^{N} R_{t}^{i} R_{t}^{j}$

The cross-market correlation is then calculated as the ratio of the cross-market covariance to the square of the cross-market dispersion. ${ }^{22}$ While the cross-market dispersion measures the degree of discrepancy across markets, the cross-market covariances and correlations provide an alternative mean to track the co-movement at each point in time.

22 The derivation of the dispersion indicator, as well as the cross-market covariance and correlation follows Adrian (2007). 


\section{ii. Principal component analysis}

If a set of series are correlated, it may be the case that their co-movements are driven by one or more common factors which are not directly observable. To estimate these factors, a factor analysis method such as the principal component analysis (PCA) is needed. In this study, the PCA is applied on the levels as well as the changes of the risk appetite measures in order to identify the respective common factors in their variations. The first component factor is generally interpreted as the common force driving the dynamics of these risk appetite measures.

PCA involves the calculation of the eigenvalue decomposition of the data covariance matrix. ${ }^{23}$ From a set of $n$ mean-centered series which are supposed to be correlated with one another, PCA extracts a new list of $p$ variables called "factors" $f_{1}, \ldots ., f_{p}(p \leq n)$ which are uncorrelated among one another. The common factors are constructed as linear combinations of the initial $n$ series. The proportion of total variation accounted for by the first $k$ factors $(k<p)$ represents the overall quality of the PCA ${ }^{24}$ One usually hopes to account for most of the original variability using a relatively fewer number of component factors. In this study, the degree of integration is measured by two criteria: a) the number of the first $k$ factors required to explain over $80 \%$ of the common variation - the less the number the better; and b) the percentage of the common variation explained by the first factor - the higher the percentage the better.

\section{iii. Haldane and Hall (1991) Kalman filter method}

The notion of convergence or integration is that the difference between two (or more) series should become arbitrarily small or they converge to some constant $c$ as time elapses, such that $\lim _{k \rightarrow \infty} E\left(X_{t+k}-Y_{t+k}\right)=0$ or $c$, where $X$ and $Y$ are the two series. The convergence may be a gradual and on-going process over time. If we expect the convergence process to take place over time from a lower to a higher level, we need a measure which would allow for such dynamic structural change. This measure will be useful in describing the process of structural change in terms of both degree and timing. The Kalman filter approach suggested by Haldane and Hall (1991) is a method that can be used to measure the time-varying convergence dynamic. ${ }^{25}$

In this study, the Haldane and Hall method estimates a simple equation via Kalman filter estimation with the signal equation as:

$$
R_{t}^{B}-R_{t}^{i}=\alpha_{i, t}+\beta_{i, t}\left(R_{t}^{B}-R_{t}^{U S}\right)+\varepsilon_{i, t}, \varepsilon_{i, t} \sim N(0, V)
$$

and the state equations as:

$$
\begin{array}{ll}
\alpha_{i, t}=\alpha_{i, t-1}+\xi_{t}, & \xi_{t} \sim N(0, U) \\
\beta_{i, t}=\beta_{i, t-1}+\mu_{t}, & \mu_{t} \sim N(0, W)
\end{array}
$$

23 Before calculating the eigenvalue of the data matrix, the original data series are pre-treated by subtracting the mean from each of the original data series of interest. The mean subtracted is the simple average of the respective original data series. This procedure is called mean centering.

24 For more details see Johnson and Wichern (1992).

25 Serletis and King (1997) and Manning (2002) use the Haldane and Hall approach to measure convergence of European Union and South East Asian equity markets respectively. Yu et al. (2007a, 2007b) also apply the approach to assess the stock and bond market integration in Asia. 
where $R_{t}^{i}$ is the monthly changes in the risk appetite measure of economy $i$ at time $t, R_{t}^{B}$ is the monthly changes in the risk appetite measure of another economy other than the US at time $t$ and $R_{t}^{U S}$ is that of the US.

We obtain the estimated parameter $\beta_{i}$ over time via Kalman filter. From Equation (A10), it is easy to show that if $R^{i}$ and $R^{B}$ converge (the changes in risk appetite of economy $i$ converge to that of another economy other than the US), we would expect $\beta_{i}$ to approach zero. Conversely, if $R^{i}$ and $R^{U S}$ converge (the changes in risk appetite of economy $i$ converge to that of the US), we would find $\beta_{i}$ to approach one. In this measure, a tendency for $\beta_{i}$ moving towards one or towards zero indicates an increasing sensitivity (and implies a higher degree of convergence) of economy i's risk appetite change to that of the US or of another economy. ${ }^{26,27}$

\section{iv. Correlation using dynamic conditional correlation (DCC) model}

Simple (or rolling) correlation analysis is among the simplest method for examining the comovement of financial markets. Basically, higher correlation between markets implies higher co-movement and greater integration between the markets. The DCC model, proposed by Engle and Sheppard (2001) and Engle (2002), is a new class of multivariate model which is particularly well suited to examine correlation dynamics among assets. The DCC approach has the flexibility of univariate GARCH but without the complexity of a general multivariate $\mathrm{GARCH}$. As the parameters to be estimated in the correlation process are independent of the number of series to be correlated, a large number of series can be considered in a single estimation. Furthermore, Wong and Vlaar (2003) show that the DCC model outperforms other alternatives in modelling time-varying correlations.

To measure conditional correlations, a two-step estimation procedure of the DCC model is used. Univariate GARCH models are first estimated for each series. The standardised residuals from the first step are then used to estimate the dynamic conditional correlations between those series. Specifically, let $z_{i, t}$ and $z_{j, t}$ be the standardised residuals of the series of economy $i$ and $j$ at time $t$ respectively, $i \neq j$. The GARCH process, as suggested in Engle (2002), is as follows:

$q_{i j, t}=\bar{\rho}_{i j}+\alpha\left(z_{i, t-1} z_{j, t-1}-\bar{\rho}_{i j}\right)+\beta\left(q_{i j, t-1}-\bar{\rho}_{i j}\right)$

and

$\rho_{i j, t}=\frac{q_{i j, t}}{\sqrt{q_{i i, t} q_{j j, t}}}$

26 By re-arranging Equation (A10), we obtain the following equation:

$$
\left(1-\beta_{i, t}\right) R_{t}^{B}+\beta_{i, t} R_{t}^{U S}-\alpha_{i, t}-\varepsilon_{i, t}=R_{t}^{i}
$$

It can be seen from the above equation that when $\beta_{i}$ approaches zero, the movement in $R^{i}$ would be increasingly influenced by that in $R^{B}$, suggesting that the two series are converging. On the other hand, when $\beta_{i}$ approaches one, the influence from $R^{B}$ is reducing while that from $R^{U S}$ is increasing, which suggests $R^{i}$ and $R^{U S}$ are converging.

27 One caveat of the Haldane and Hall approach is that the conclusion of whether an economy's risk appetite is converging or diverging may well differ according to the choices of the other two economies in the signal equation. 
where $q_{i j}$ is the off-diagonal elements of the variance-covariance matrix, $\bar{\rho}_{i j}$ is the unconditional expectation of the cross product $z_{i, t} z_{j, t}$ and $\rho_{i j, t}$ is the conditional correlation between the series of economy $i$ and $j$ at time $t{ }^{28}$ In the main text, DCCs are derived for the relationships between the changes in the risk appetite measures and the stock market return performance, as well as between the levels of the risk appetite measures and the 3-month as well as the 10-year government bond yields.

The Ljung-Box tests for serial correlation, as shown by the $\mathrm{Q}$ statistics in Table A1, provide evidence of serial correlation in most of the squared level series of the levels as well as the changes in the risk appetite measures, the returns (in log differences) of the stock market indices as well as the 3-month and 10-year government bond yield series. Thus, the specification of a GARCH model is appropriate.

Table A1

Ljung-Box $Q(3)$ statistics for serial correlation test

\begin{tabular}{c|c|c|c|c|c|c}
\hline & \multicolumn{2}{|c|}{ Risk appetite measure } & $\begin{array}{c}\text { Stock market } \\
\text { index }\end{array}$ & $\begin{array}{c}\text { 3-month } \\
\text { bond }\end{array}$ & 10-year bond \\
\hline \multirow{2}{*}{ US } & $\begin{array}{c}\text { (squared } \\
\text { level) }\end{array}$ & $\begin{array}{c}\text { (squared } \\
\text { change) }\end{array}$ & $\begin{array}{c}\text { (squared } \\
\text { return) }\end{array}$ & \multicolumn{2}{|c}{ (squared yield level) } \\
UK & 1.81 & 4.40 & $10.67^{\star *}$ & $213.62^{\star *}$ & $106.37^{\star *}$ \\
Germany & $9.47^{\star *}$ & 4.87 & $23.04^{\star *}$ & $193.37^{\star *}$ & $124.61^{\star *}$ \\
Japan & $45.41^{\star *}$ & $7.01^{*}$ & $11.20^{\star *}$ & $175.69^{\star *}$ & $159.47^{\star *}$ \\
HK SAR & 1.75 & $36.39^{\star *}$ & 3.12 & $185.06^{\star *}$ & $150.38^{\star *}$ \\
\hline
\end{tabular}

** indicates significance at the $5 \%$ confidence level. * indicates significance at the $10 \%$ confidence level. Q(3) is the Ljung-Box statistic based on the squared level of the monthly return series up to the third order. The statistics are asymptotically distributed as $\chi^{2}(3)$. The critical value of $\chi^{2}(3)$ at the $5 \%$ level is 7.81 , at the $10 \%$ level is 6.25 .

Source: HKMA staff estimates.

28 See Engle (2002) for a detailed description of the simple DCC model and the estimation procedure. 


\section{References}

Adjaoute, K. and J. P. Danthine (2003): "European Financial Integration and Equity Returns: A Theory-based Assessment", in Gaspar, V. et al. The Transformation of the European Financial System, European Central Bank.

Adrian, T. (2007): "Measuring Risk in the Hedge Fund Sector", Federal Reserve Bank of New York Current Issues in Economics and Finance 13(3), March/April.

Baele, L., A. Ferrando, P. Hordahl, E. Krylova and C. Monnet (2004): "Measuring Financial Integration in the Euro Area", European Central Bank Occasional Paper 14.

Coudert, V. and M. Gex (2006): "Can Risk Aversion Indicators Anticipate Financial Crises?", Bank of France Financial Stability Review No. 9, 67-87.

Engle, R. F. (2002): "Dynamic Conditional Correlation: A Simple Class of Multivariate Generalized Autoregressive Conditional Heteroskedasticity Models", Journal of Business and Economic Statistics 20(3), 339-350.

Engle, R. F. and K. Sheppard (2001): "Theoretical and Empirical Properties of Dynamic Conditional Correlation Multivariate GARCH", NBER Working Paper 8554.

Gai, P. and N. Vause (2006): "Measuring Investors' Risk Appetite", International Journal of Central Banking Vol 2, 167-188.

Haldane A. G. and S. G. Hall (1991): "Sterling's Relationship with the Dollar and the Deutschemark: 1976-89", The Economic Journal 101(406), 436-443.

Illing, M. and M. Aaron (2005): "A Brief Survey of Risk-Appetite Indexes", Bank of Canada Financial System Review June, 37-43.

Johnson, R. A. and D. W. Wichern (1992) Applied Multivariate Statistical Analysis, Third Edition, Upper Saddle River, New Jersey: Prentice-Hall, Inc.

Joliffe, I. T. (1972): "Discarding Variables in a Principal Component Analysis I: Artificial Data", Applied Statistics Vol 21, 2, 160-173.

Kaiser, H. F. (1960): "The Application of Electronic Computers to Factor Analysis", Educational and Psychological Measurement Vol 20, 141-151.

Korajczyk, R. A. (1995): "A Measure of Stock Market Integration for Developed and Emerging Markets", The World Bank Policy Research Working Paper 1482.

Kumar, M. S. and A. Persaud (2002): "Pure Contagion and Investors' Shifting Risk Appetite: Analytical Issues and Empirical Evidence", International Finance 5, 401-436.

Manning, N. (2002): "Common Trends and Convergence? South East Asian Equity Markets, 1988 - 1999", Journal of international Money and Finance 21, 183-202.

Serletis, A. and M. King (1997): "Common Stochastic Trends and Convergence of European Union Stock Markets", The Manchester School 65(1), 44-57.

Solnik, B. and J. Roulet (2000): "Dispersion as Cross-sectional Correlation", Financial Analysts Journal 56(1), 54-61.

Tarashev, N., K. Tsatsaronis and D. Karamptatos (2003): "Investors' Attitude Toward Risk: What Can We Learn From Options", BIS Quarterly Review, June, 57-66.

Wong, A. S. K. and P. J. G. Vlaar (2003): "Modelling Time-varying Correlations of Financial Markets", De Nederlandsche Bank NV Research Memorandum 739/0319.

Yu, Ip-wing, L. Fung and C. S. Tam (2007a): "Assessing Financial Market Integration in Asia Equity Markets", Hong Kong Monetary Authority Working Paper 04/2007.

(2007b): "Assessing Bond Market Integration in Asia", Hong Kong Monetary Authority Working Paper 10/2007. 